\title{
Tangence
}

Hélène Dorion, Les états du relief, Montréal/Chaillé-sous-les-Ormeaux, Éditions du Noroît/Le Dé bleu, 1991, 87 p.

\section{Marie Bélisle}

Numéro 36, mai 1992

La lecture littéraire

URI : https://id.erudit.org/iderudit/025719ar

DOI : https://doi.org/10.7202/025719ar

Aller au sommaire du numéro

\section{Éditeur(s)}

Tangence

ISSN

0226-9554 (imprimé)

1710-0305 (numérique)

Découvrir la revue

Citer ce compte rendu

Bélisle, M. (1992). Compte rendu de [Hélène Dorion, Les états du relief,

Montréal/Chaillé-sous-les-Ormeaux, Éditions du Noroît/Le Dé bleu, 1991, 87 p.]

Tangence, (36), 117-119. https://doi.org/10.7202/025719ar d'utilisation que vous pouvez consulter en ligne.

https://apropos.erudit.org/fr/usagers/politique-dutilisation/ 


\section{Hélène Dorion, Les états du relief, Montréal/Chaillé-sous-les- Ormeaux, Éditions du Noroît/Le Dé bleu, 1991, 87 p.}

Hélène Dorion est une auteure prolifique: dix publications en huit ans, dont trois en 1990 et trois en 1991. Par cela même, sa production paraît s'inscrire dans un rapport au temps qui télescope l'espace (poétique), où la difficulté de durer est contrée par la constance. D'un recueil à l'autre, comme d'un poème à l'autre, le parcours narratif gomme l'intervalle ("prolongé"?) ${ }^{1}$ entre les différents états du relief.

Les livres, et les textes qui les constituent, apparaissent comme des chemins de traverse entre le réel et la fiction qu'ils font advenir. Par exemple, ces quelques titres de Dorion: Les corridors du temps (Écrits des Forges, 1988), La vie, ses fragiles passages (Le Dé bleu, 1990), Passerelles et poussières (Brandes, 1991); par exemple, ces extraits des États du relief: "j'ai rêvé de mots que l'on glissait / comme des passerelles entre nos vies" (p. 37); "suis-je un corridor où passe/une histoire défigurée" (p. 23).

Pour Hélène Dorion, le poème n'est pas une fin en soi: il acquiert une fonction de transitivité. Non plus seulement objet (serait-ce d'art), le poème permet de saisir l'émotion et d'appréhender le réel: "peut-être le poème / suffit-il pour retrouver ce qu'on attend "(p. 76); "l'émotion finit toujours par quelques mots" (p. 44); le poème devient sujet de l'écriture même.

Ainsi, le texte nous est donné comme seul instrument de la permanence, comme seul obstacle à l'absence et à l'éphémère, tels ces "Poèmes de retour/Qui essaient de ramener/ce qui s'éloigne chaque jour/des mots attendent/à travers le nom de l'autre / que froisse l'absence. (p. 71); ainsi, la phrase nous est donnée comme seule immanence possible: "Quelque chose de toi vivrait/plus longtemps que toi / [...] tu circules / en un présent qui reconduit ton corps / dans la vie privée de la phrase" (p. 17).

Il n'est pas étonnant, dès lors, que l'écriture suive à la trace ce réel dont elle seule peut assurer la survivance, qu'elle s'attache

1 Hélène Dorion, L'intervalle prolongé, suivi de La cbute requise, SaintLambert, Éditions du Noroît, coll. *L'instant d'après «, 1983. 
à la simplicité et à la clarté de ces mots qui seuls peuvent faire advenir ce qui n'est pas; car c'est "le territoire du familier / qui tisse la phrase" (p. 16). L'écriture ici affiche sa lisibilité, au point parfois de mimer la parole, la lettre ou le journal, qui surgissent alors, à peine déguisés par les blancs de fin de vers: "je ne sais plus / poser sur la douleur de vivre/la force de vivre encore" (p. 49); "tu te perds chaque fois / tu croises cet amour / auquel je n'arrive pas / à mettre fin " (p. 56).

Il semble donc y avoir chez Hélène Dorion un choix de conserver au poème un effet de réel, une décision esthétique portée par une certaine conception de l'écriture: "pourrais-je / ne pas consentir à l'abandon / qui est le pari de l'écriture" (p. 15); "les mots ne sont pas ailleurs / que dans cette vie à laquelle je cède / ouvrant tous les cahiers que l'on dit / intimes pour mieux saisir / comment les choses se passent/de l'autre côté de soi " (p. 13), écrit-elle, exposant dans le poème lui-même ses assises manifestes.

Ce parti pris détermine, pouvons-nous croire, la syntaxe des poèmes, où la phrase demeure reconnaissable, et leur lexique, où dominent les mots du langage courant. En effet, même sans céder à la tentation mathématique, comment ne pas remarquer les nombreuses occurrences de certains mots (intime, phrase, mot, désir, vivre, vie, regard, amour, aimer, tendresse, fragile, absence, visage), comme si le recueil était constitué d'un seul poème dont les fragments reprendraient ad libitum quelques mot(if)s, afin de conjurer le silence, afin de laisser dans la phrase l'évidence de la trace.

Ce caractère itératif, ce phénomène de reprise marque la trame même du texte sur le plan lexical, nous l'avons vu, mais aussi sur le plan de la syntaxe par un travail anaphorique des incipits des textes: "Qui/sommes-nous dans la nuit", "Qui/ sommes-nous dans la nuit", "Qui sommes-nous - Beyrouth un avion" (p. 21, 22, 23); "Comment guérir ", "Comment laisser murmurer" (p. 40 et 42); "Sans autre voix", "Sans autre visage" (p. 58 et 60); "On finit par suivre ", "On finit par répondre ", "On finit par guérir ", "On finit par répondre" (p. 79, 80, 81, 82). Et le titre d'une des séries, "Poèmes de retour", prend une signification qui rejaillit alors sur l'ensemble du recueil.

Les états du relief, malgré la découpe précise des poèmes et des sections du recueil, porte donc les marques de la continuité. Ce "relief " dont les poèmes exposent les états est peu accidenté: on s'y glisse sans difficulté, sans avoir à craindre la déroute. Car, 
par cet apparent refus de l'épithète rare, de la déconstruction syntaxique, de l'accumulation des métaphores, et par ce choix d'une écriture itérative et narrative, Hélène Dorion livre à la lectrice, au lecteur, le fil du poème ${ }^{2}$ et l'invite à suivre ce parcours intime: "J'écris dans les modulations / de l'intimité je traverse / chacun des replis / jusqu'à l'insignifiance de ce qui sépare / de soi-même ce point de rupture / quand le livre se referme/je ne suis plus ailleurs / que dans ce récit . (p. 18).

\section{Marie Bélisle}

2 "Je reste là, immobile tout près d'Ariane", Hélène Dorion, Les retouches de l'intime, Saint-Lambert, Éditions du Noroît, 1987, p. 15 